\title{
The connection of the Indonesian Throughflow, South Indian Ocean Countercurrent and the Leeuwin Current
}

\author{
Erwin Lambert, Dewi Le Bars, and Wilhelmus P. M. de Ruijter \\ Institute of Marine and Atmospheric Sciences Utrecht, Utrecht University, Utrecht, the Netherlands \\ Correspondence to: Erwin Lambert (erwin.lambert@uib.no)
}

Received: 18 August 2015 - Published in Ocean Sci. Discuss.: 25 September 2015

Revised: 15 April 2016 - Accepted: 5 May 2016 - Published: 2 June 2016

\begin{abstract}
East of Madagascar, the shallow "South Indian Ocean Counter Current (SICC)" flows from west to east across the Indian Ocean against the direction of the winddriven circulation. The SICC impinges on west Australia and enhances the sea level slope, strengthening the alongshore coastal jet: the Leeuwin Current (LC), which flows poleward along Australia. An observed transport maximum of the LC around $22^{\circ} \mathrm{S}$ can likely be attributed to this impingement of the SICC. The LC is often described as a regional coastal current that is forced by an offshore meridional density gradient or sea surface slope. However, little is known about the controls of these open-ocean gradients. The regional circulation system is embedded in the subtropical "super gyre" that connects the Indo-Pacific via the Tasman Gateway and the Indonesian passages. The Indonesian Throughflow (ITF) circulates through the Indian Ocean back into the Pacific south of Australia. This return pathway appears to be partly trapped in the upper layer north of an outcrop line. It is redirected along this outcrop line and joins the eastward flow of the SICC. To study the connection of the basin-scale and the inter-oceanscale dynamics, we apply both an ocean general circulation model and a conceptual two-layer model. Shutdown of the ITF in the models leads to a large decrease in Leeuwin Current transport. Most of the SICC was found to then reconnect to the internal gyre circulation in the Indian Ocean. ITF, SICC and LC thus appear to be dynamically connected.
\end{abstract}

\section{Introduction}

In the upper layer of the South Indian Ocean (SIO) three unique anomalous currents have been identified: the Leeuwin Current (LC; Cresswell and Golding, 1980), which flows poleward along Australia; the South Indian Ocean Counter Current (SICC; Palastanga et al., 2007), which flows from Madagascar to Australia in the upper $\pm 300 \mathrm{~m}$; and the Indonesian Throughflow (ITF; Godfrey and Golding, 1981), which flows through the Indonesian passages from the tropical Pacific to the Indian Ocean. The LC is unique as an eastern boundary current. Satellite observations show that this is the only eastern boundary region of enhanced mesoscale eddy activity (Schouten et al., 2005; Morrow and Birol, 1998). Across the SIO, the SICC flows against the direction of the wind (curl)-driven Sverdrup circulation that moves underneath it. In contrast to other subtropical countercurrents (STCCs) which dissolve in the gyre, the SICC spans the full width of the basin. Large vertical shear between these opposing currents leads to (baroclinic) instability and eddies that propagate westward (Palastanga et al., 2007; Jia et al., 2011). The ITF is part of the subtropical "super gyre", a wind-driven circulation which connects the Pacific, Indian and Atlantic oceans via the Indonesian passages and the Agulhas and Tasman gateways (Speich et al., 2007; de Ruijter, 1982; Ridgway and Dunn, 2007). Hypotheses on the nature and coherence of this shallow circulation system range from localised frontal jets to a system that connects the Indonesian Throughflow, the Mozambique Channel and Agulhas Current, the SICC and the Leeuwin Current System. In this study, we provide evidence supporting this latter theory of a large-scale connectivity.

Most studies of the Indian Ocean (IO) have been complementary in focusing on either the western or the eastern 

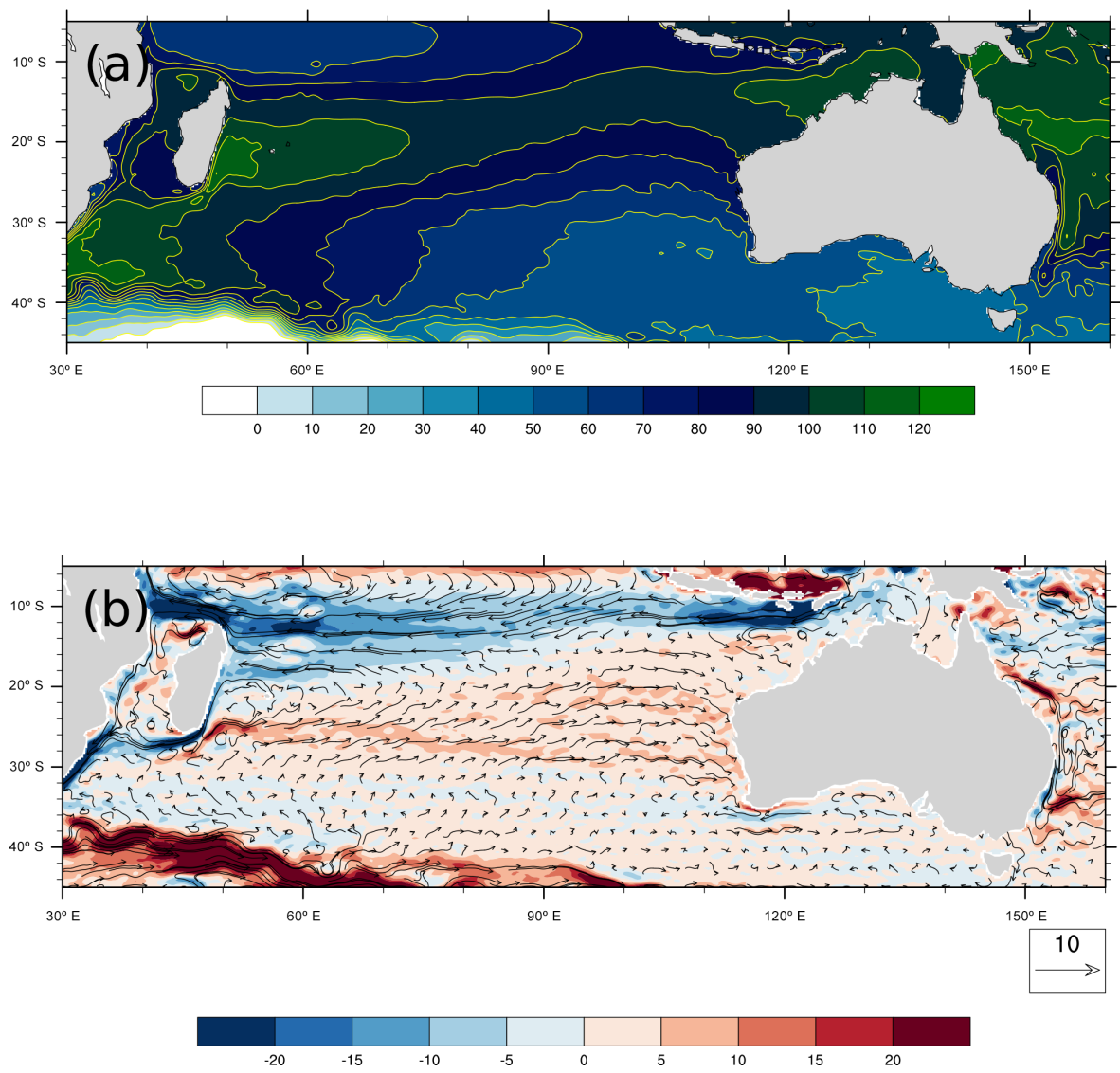

Figure 1. (a) Mean dynamic topography ( $\mathrm{cm}$ ) from product MDT_CNES-CLS13. (b) Derived geostrophic velocities $\left(\mathrm{cm} \mathrm{s}^{-1}\right.$ ), where positive values indicate an eastward component.

sector. Observations in the west have suggested the Agulhas Retroflection and Return Current as the origin of the SICC (Nauw et al., 2008). In the east, observations (Smith et al., 1991; Woo et al., 2006; Woo and Pattiaratchi, 2008; Weller et al., 2011) and Lagrangian models (Song et al., 2004; Domingues et al., 2007; Valsala and Ikeda, 2007; van Sebille et al., 2014) have identified both tropical (including ITF) and subtropical waters as a source for the LC. Basinwide observations indicate that westward flow around $10^{\circ} \mathrm{S}$ (partly ITF) and eastward flow near $25^{\circ} \mathrm{S}$ (SICC) cross the entire basin of the Indian Ocean (see Fig. 1). These findings indicate a large-scale connectivity between the east and west. However, understanding of the dynamics and connection between these shallow currents - the LC, the SICC and the ITF - is still limited.

The Leeuwin Current plays an important role in regional climate and ecology (Waite et al., 2007). Linear theory cannot explain such a poleward boundary current along an eastern boundary. Early studies have pointed toward observed meridional gradients in density and steric height as a forcing agent for the LC and the influence of the ITF in reinforcing these gradients (Godfrey and Ridgway, 1985; Weaver and Middleton, 1989). Theories on the coastal trapping of the
LC have focused on vertical diffusion of Rossby waves (McCreary et al., 1986) and interaction with the continental shelf (Csanady, 1978, 1985). An ongoing programme is evaluating these various proposed mechanisms (Furue et al., 2013; Benthuysen et al., 2014) but leaves the problem of large-scale forcing and connectivity of the LC unanswered. To understand this large-scale forcing, one needs to understand the origin of the off-shore meridional gradients, which hints at an important role of the SICC.

The SICC shows similarities to other STCCs which have been identified in the North Pacific (Uda and Hasunuma, 1969), South Pacific (Merle et al., 1969), North Atlantic (Reid and Mantyla, 1978) and South Atlantic (Tsuchiya, 1985). These zonal currents have the clearest signature near $20-25^{\circ} \mathrm{N} / \mathrm{S}$ in the western part of the basins. Suggested driving mechanisms are Ekman convergence (Takeuchi, 1984), isothermal convergence (Cushman-Roisin, 1984), shock formation of mixed-layer depth (de Ruijter, 1983), convergence of Rossby waves (Dewar, 1991) and mode water formation (Kobashi and Kubokawa, 2012). No single mechanism has been identified as the dominant one, and all may play a part in the actual frontogenesis forming these STCCs. All studies do, however, agree that the combination of buoyancy forcing 
and wind stress convergence establishes the observed zonally oriented fronts with associated baroclinic frontal jets. Because these fronts are expressed in a sharp gradient of isopycnal depth (Fig. 2), these isopycnals can outcrop along the fronts of the STCCs. In the south-east Indian Ocean, these forcing components vary clearly at seasonal, interannual and decadal timescales, as shown elegantly by Jia et al. (2011) using a variety of satellite data. They also showed the associated modulation of baroclinic instability and eddy kinetic energy (Palastanga et al., 2007; Jia et al., 2011).

The Indonesian Throughflow, due to its advection of warm and fresh water, affects the hydrography in the South Indian Ocean. The effect on the circulation was first studied by Hirst and Godfrey (1993), who performed simulations using a general circulation model (GCM). In one run, they applied realistic bathymetry; in a second run, the Indonesian passages were closed. In the first run allowing the ITF, a shallow south-eastward jet appeared near the latitude where the SICC is observed, down to the south-western tip of Australia. In the second run, blocking of the ITF weakened this shallow circulation. They suggested that the Leeuwin Current System (LCS) is part of this shallow circulation. A modelintercomparison study of three models of varying complexity supported their conclusions (McCreary et al., 2007), yet both studies were based on coarse-resolution simulations. The response of the narrow SICC and LC could therefore not be addressed. Le Bars et al. (2013) were the first to perform comparable simulations, with open and closed Indonesian passages, using a GCM at eddy-resolving resolution. Since analysis of these model results was restricted to barotropic circulation, no conclusions could be drawn on the SICC and LC systems. We will use these data to revise the effect of the ITF on the "realistically" simulated SICC and LC.

Three shallow currents have been identified in the South Indian Ocean: the Leeuwin Current, the South Indian Ocean Countercurrent and the Indonesian Throughflow. In this study, we aim to understand if and how these currents form a connected system. We primarily focus on the LC and the SICC and address the following questions: what is the dynamic connection between the SICC and the LC? How can the general features of the shallow circulation in the SIO be understood from surface forcing? What is the role of the ITF in this system? And why are poleward eastern boundary currents of similar strength to the LC not found in other subtropical basins?

To answer these questions, two models of different complexity were used. First, an ocean GCM is run at high and coarse resolution to validate against the results of Hirst and Godfrey (1993) and to show the impact of inertia on the sensitivity of the LC and SICC to the ITF. Second, a conceptual regional two-layer model is used to simulate the general shallow circulation features of the SIO from surface forcing and to reveal the sensitivity of these features to removal of the Pacific influence through the ITF. In Sect. 2, properties and configuration of both models are presented. Model results are presented in Sect. 3. With both models, sensitivity of the circulation to the ITF is presented in Sect. 4, which is followed by concluding remarks in Sect. 5 .

\section{Model configurations}

Two models were used in this study on the dynamics of the shallow circulation in the South Indian Ocean, an ocean GCM and a conceptual two-layer model. In this section, we describe the basic properties and the configuration of both models.

\subsection{General circulation model: Parallel Ocean Program}

The Parallel Ocean Program (POP; Dukowicz and Smith, 1994) is an ocean-only general circulation model solving the primitive equations on a horizontal grid with an average resolution of $0.1^{\circ}$ and 42 vertical layers. The atmospheric state and precipitation were taken from the Coordinated Ocean-ice Reference Experiments (CORE) data set (Large and Yeager, 2004), wind stress was computed offline using Hurrell Sea Surface Temperature climatology (Hurrell et al., 2008) and evaporation and sensible heat flux were calculated online.

For the GCM analysis, we used data from the simulations performed by Le Bars et al. (2013). After a spin-up of 75 years as described by Maltrud et al. (2010), two simulations were performed: one with realistic bathymetry and one with closed Indonesian passages in a similar fashion to Hirst and Godfrey (1993). Both were run for another 105 model years, of which the last 50 years of simulation were averaged to approximate a steady state. Simulations were repeated on a horizontal grid with average resolution of $1.0^{\circ}$, allowing for validation against previous modelling studies.

\subsection{Conceptual model: Hallberg Isopycnal Model}

The Hallberg Isopycnal Model (HIM; Hallberg, 1997, 2000) is a regional ocean-only model solving the hydrostatic primitive equations in spherical coordinates on an Arakawa $\mathrm{C}$-grid. Using the vorticity scheme of Arakawa and Hsu (1990), the model allows for arbitrarily thin layers and hence admits isopycnal outcrop. The model is configured to an idealised representation of the Indian and Pacific oceans with horizontal resolution of $0.2 \times 0.2^{\circ}$, separated by an elongated island representing Australia (Fig. 3). A minimum of idealised forcing terms is applied to simulate a mid-ocean eastward jet in the western basin, and a westward jet along the northern boundary of Australia with a predictable return pathway. These jets will be interpreted as the SICC and the ITF respectively.

The model eastern basin is scaled down compared to the actual Pacific Ocean; by adjusting the wind stress amplitude, the model can simulate a realistic Pacific Sverdrup transport. The flat bottom is at a depth of $1500 \mathrm{~m}$ below the free surface, which is the approximate depth of the wind-driven circula- 


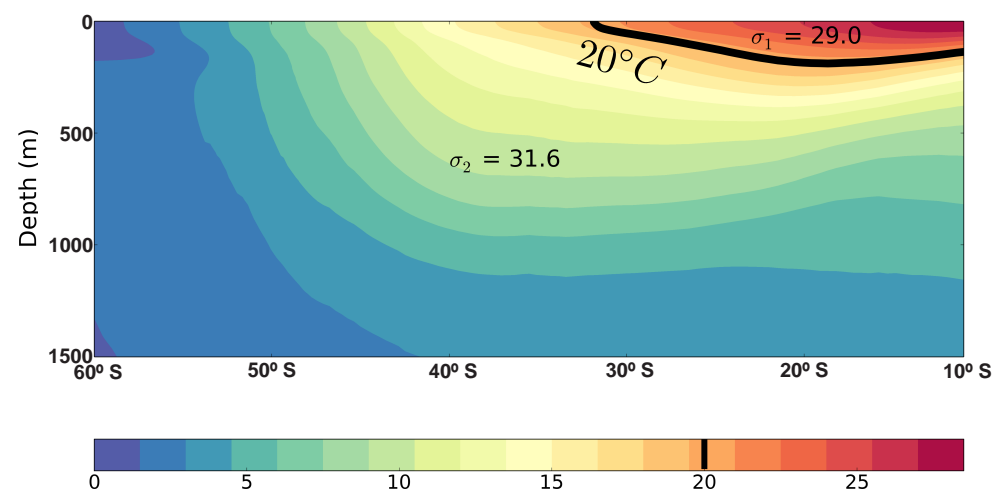

Figure 2. Meridional section of temperature $\left({ }^{\circ} \mathrm{C}\right.$ ) at $80^{\circ} \mathrm{E}$ from Argo floats (ARIVO project; Gaillard and Charraudeau, 2008). The 20 ${ }^{\circ} \mathrm{C}$ isotherm is used to divide the basin into an upper and lower layer. For both layers, average relative densities $\sigma$ are denoted, which are used for defining the stratification of the two-layer model. The isotherm shows outcrop near $30^{\circ} \mathrm{S}$, marking the southern boundary of the upper layer.
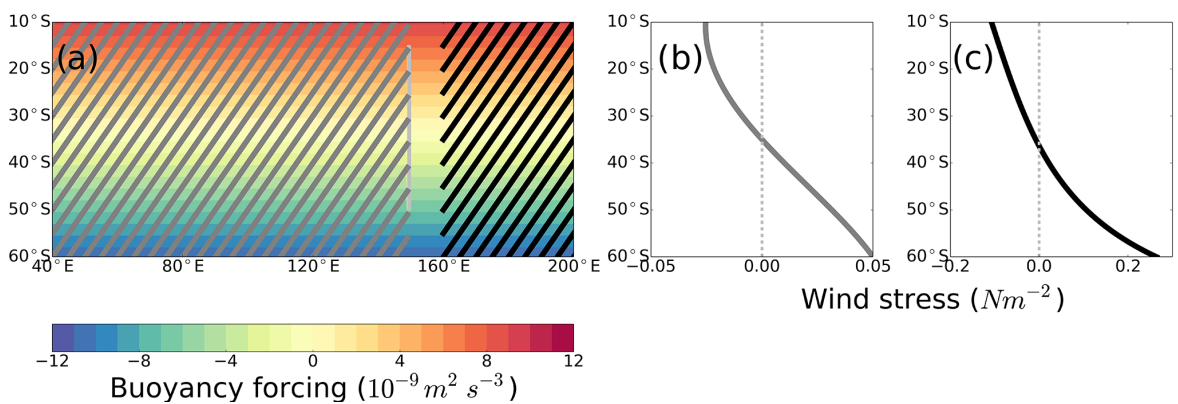

Figure 3. Configuration of the conceptual two-layer model. (a) Model domain, applied buoyancy forcing (shading) and two areas where wind stress is applied (hatches). The light grey area at $150^{\circ} \mathrm{E}$ indicates the elongated island. (b) Wind stress simulating a gyre (grey) and (c) ITF (black) applied to respective areas as indicated in panel (a).

tion. An elongated island is chosen to represent Australia. A two-layer system allows for representation of the baroclinic structure of the Indian Ocean. As shown by McCreary et al. (1986), such a configuration with vertical walls is able to produce a poleward eastern boundary current, although it cannot sustain a barotropic transport. As the initial state, the interface depth between these layers was taken uniformly at $100 \mathrm{~m}$, a typical depth of both the SICC and LC.

Stratification of the model is based on the $20^{\circ} \mathrm{C}$ isotherm (Fig. 2), determined using Argo float data from the ARIVO project (Gaillard and Charraudeau, 2008) over the corresponding domain and depths. Density of the lower layer is taken as the average density between the isotherm and $1500 \mathrm{~m}$ depth. The respective densities are $\rho_{1}=1029.0$ and $\rho_{2}=1031.6 \mathrm{~kg} \mathrm{~m}^{-3}$. After spin-up, as described below, the mean interface depth is $200 \mathrm{~m}$, giving mean depths of the layers $H_{1}=200$ and $H_{2}=1300 \mathrm{~m}$. This gives an internal Rossby radius of $22 \mathrm{~km}$.

To investigate both inertial and viscous response in the boundary layer regions, we applied two values for horizontal Laplacian viscosity: $A_{\mathrm{H}}=100$ and $10^{4} \mathrm{~m}^{2} \mathrm{~s}^{-1}$, giving a boundary layer scale of 20 and $80 \mathrm{~km}$ respectively. The vis- cous regime may be compared to coarse simulations from previous studies (Hirst and Godfrey, 1993; McCreary et al., 2007). Along the lateral boundaries we applied no-slip conditions.

The temperature structure in the Indian Ocean clearly reflects the meridional gradient in surface heat flux (Fig. 2). To simulate the effect of surface heating and cooling and freshwater fluxes, we applied a total buoyancy flux, as in Haney (1971), prescribing a surface boundary condition:

$$
\frac{B \rho_{0}}{g}=-K_{v} \frac{\partial \rho}{\partial z} \text {. }
$$

Here, $B$ is the surface buoyancy flux in $\mathrm{m}^{2} \mathrm{~s}^{-3}$. The maximum applied value for $B$ of $12 \times 10^{-9} \mathrm{~m}^{2} \mathrm{~s}^{-3}$ is equivalent to a surface heat flux of $31 \mathrm{~W} \mathrm{~m}^{-2}$, a moderate value compared to estimates by Haney (1971). The applied buoyancy forcing has a constant meridional gradient and is independent of longitude (Fig. 3). The total buoyancy flux is conserved over the ocean surface.

Wind stress is applied separately over two regions. In the western basin (grey hatches in Fig. 3), a sinusoidal wind stress is applied, corrected for curvature due to the spheri- 
cal coordinates. This forces a single Sverdrup gyre west of the island. In the eastern basin (black hatches in Fig. 3), a wind stress with constant curl is applied, again corrected for curvature. This pattern forces a constant northward Sverdrup transport of $15 \mathrm{~Sv}$, which circulates along the northern, western and southern boundaries of the basin. The westward flow along the northern boundary represents the ITF in this model.

The combined forcing of buoyancy fluxes and wind stress can induce frontogenesis, resulting in outcrop of the interface. This effectively reduces part of the basin to a onelayer system which has to equilibrate laterally. After 50 model years, total energy in the system was found to be approximately constant. We therefore averaged the output over model years $45-55$ to resemble a quasi-steady state. Over this period, the mean interface depth increased by 5-10\% in each model run as a result of the energy imbalance.

Linear theory allows for qualitative prediction of the resulting circulation, and it is instructive to do so before analysing the results. The applied wind pattern drives a depth-integrated circulation which is a combination of a Sverdrup gyre in the western basin and a jet-like circulation along the northern, western and southern boundaries, connecting to a broad constant northward flow in the eastern basin. The meridional gradient in buoyancy fluxes produces a baroclinic structure of eastward flow in the upper layer and westward flow in the lower layer, according to thermal wind balance:

$$
\frac{\partial u}{\partial z}=\frac{g}{\rho_{0} f} \frac{\partial \rho}{\partial y} .
$$

Here, $u$ is the zonal velocity in metres per second $\left(\mathrm{m} \mathrm{s}^{-1}\right)$. Frontogenesis can reinforce this meridional gradient (de Ruijter, 1983; Takeuchi, 1984; Cushman-Roisin, 1984), narrowing and enhancing the baroclinic structure, making the eastward flow in the upper layer more jet-like, similar to the observed SICC.

\section{Results}

In the two-layer solutions, the eastward current appears to be connected to the interface outcrop. The basic structure of the circulation is that of a gyre in each of the basins with a supergyre wrapping around it and flow through both basins (e.g. Pedlosky et al., 1997). This is what one can see in the northern strip, between 10 and $15^{\circ} \mathrm{S}$ (Fig. 6b), where the wind forcing in the eastern basin is set to zero, but buoyancy forcing drives a $3 \mathrm{~Sv}$ gyre. The mismatch with the Indian Ocean gyre is corrected in a zonal boundary layer west of the northern termination of the "island". At this value of the viscosity parameter, a large part of the northern Pacific inflow makes an excursion along the northern boundary into the western boundary layer of the Indian Ocean (Agulhas), then back northward in a gyre-like flow in the interior of the IO and eastward in the free zonal boundary layer, exiting through the gateway north of the island.

Adding the ITF (and thus also the mismatch) by adding northward forcing wind curl over the "Pacific" has much impact on the flow in the eastern IO (Fig. 7b). The zonal front strengthens, and the mean interface is $30 \mathrm{~m}$ deeper than in absence of wind stress in the eastern basin. Consequently, the zonal eastward jet at $\pm 35^{\circ} \mathrm{S}$ gets stronger and is found to continue straight to the island due to the larger inertia, then head southward (as a Leeuwin Current) and exit around the southern tip into the Pacific western boundary layer. Part of it stays in the IO and flows north-eastward where it connects to the SEC and SECC system.

In the case with larger viscosity (Fig. 7a), the freeboundary layer flow west of the southern part of the island curves toward and around the southern tip. North of the island, the wider viscous boundary layer now fills the gateway and blocks the IO flow to exit through the northern passageway. Almost all flow entering through the northern passage can only exit south of "Tasmania". The jet-like structure of these zonal boundary layers induces the interface outcrop and associated fronts.

Steady-state solutions of the GCM simulations show a shallow current system in the viscous regime (Fig. 4a). The corner shape geometry of south Australia-Tasmania induces a jump in Sverdrup transport across the corner's latitude. That is matched by a viscous free-boundary layer structure with westward flow south of the discontinuity and eastward north of it. At eddy-resolving resolution this is much clearer (Fig. 4b); here, a compact poleward flowing Leeuwin Current emerges.

Both GCM simulations show a zonal flow east of Madagascar, fanning out broadly in the viscous case east of $90^{\circ} \mathrm{E}$ while bifurcating into several branches in the eddy-resolving case. This is the SICC system. A similar structure has recently been identified and analysed from observations (e.g. Menezes et al., 2013).

The northern branch of the model SICC reaches the North West Shelf, where it feeds into the coastal jet. The southern branch reaches Australia just south of the North West Cape (NWC). Cross-shore transects, taken at regular intervals of $2^{\circ}$ along the west Australian coast, reveal that the LC transport (Fig. 5) upstream of the NWC $\left(22^{\circ} \mathrm{S}\right.$, transect F) is low. A sharp increase is found from approximately 0.5 to $2.5 \mathrm{~Sv}$ just south of the NWC. This is the latitude of maximal SICC strength, and it suggests that the SICC directly connects to the LC and, in fact, largely determines its strength and existence.

As expected, the viscous circulation (Fig. 7a) shows features similar to those found in the coarse-resolution GCM results. A boundary current flows east and eventually bends south-eastward to converge toward the south-western point of the island as described below. This leads to large values of velocity shear along this outcrop line, baroclinic instabil- 

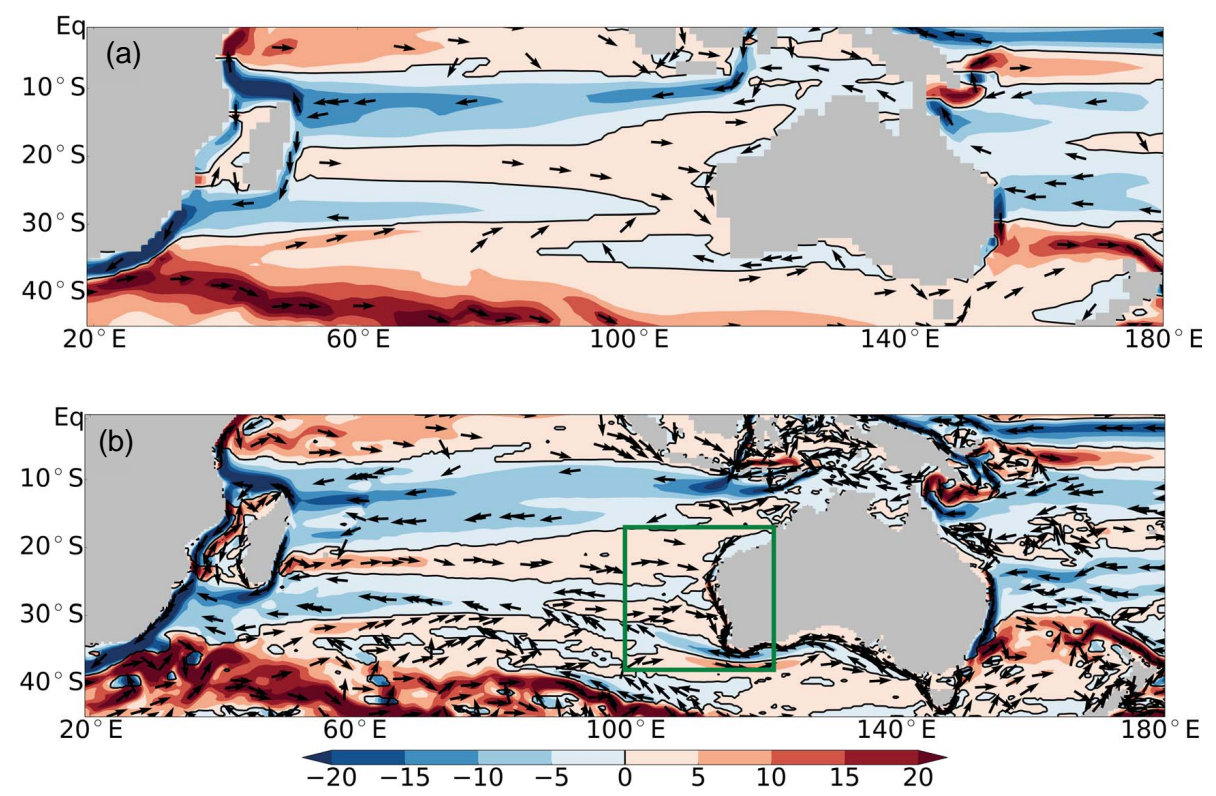

Figure 4. Steady-state horizontal velocities averaged over the top $200 \mathrm{~m}\left(\mathrm{~cm} \mathrm{~s}^{-1}\right)$ from the GCM simulations. (a) Coarse resolution $\left(1.0^{\circ}\right)$, (b) eddy-resolving resolution $\left(0.1^{\circ}\right)$. Positive values indicate an eastward component. Unit vectors are added at local maxima to show the direction of the flow. The green box indicates the area shown in Fig. 5a.
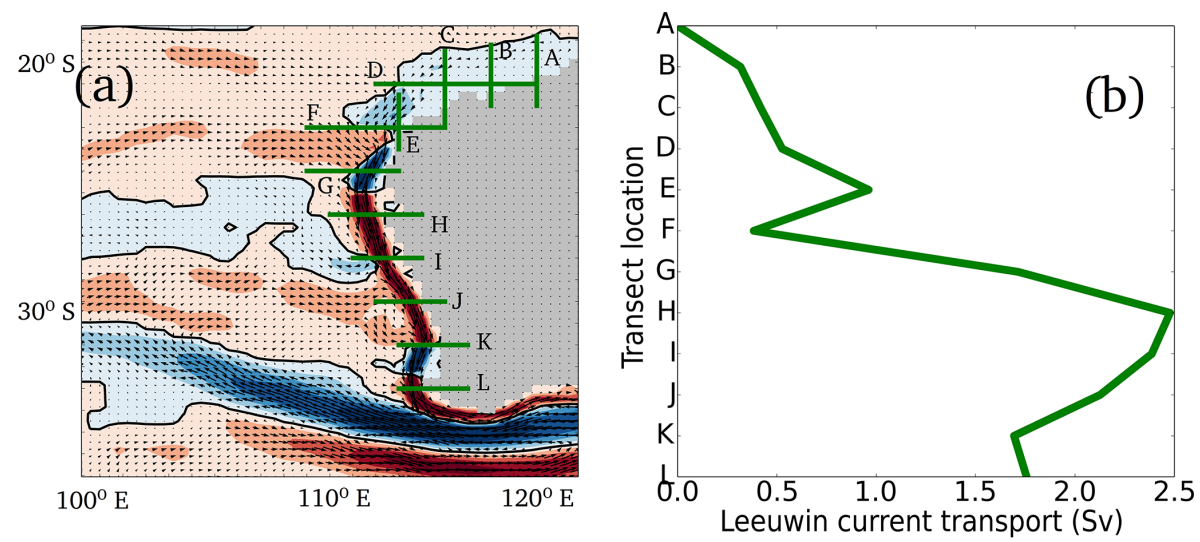

Figure 5. (a) Inlet from Fig. 4 with indicated transects along the western coast. Transects are taken at intervals of $2^{\circ}$ along the coast. Labels A-L are ordered from up- to downstream, where A, B, C and E are meridional sections, and the others zonal. (b) Cross-transect velocities are integrated down to the depth of zero velocity to give an LC transport. This depth increases monotonically from $150 \mathrm{~m}$ at transect A to $300 \mathrm{~m}$ at transect L. Transect F marks the latitude of the North West Cape: $22^{\circ} \mathrm{S}$.

ity and the formation of mesoscale eddies (Palastanga et al., 2007).

To resolve the inertial regime, the simulation was repeated with a smaller lateral viscosity of $100 \mathrm{~m}^{2} \mathrm{~s}^{-1}$ (Fig. 7b). Due to rectification of the associated modes, the mid-ocean jet flows almost zonally toward the western coast of the island. Against the boundary, it sets up a pressure gradient and induces a coastally trapped poleward current, much like the observed Leeuwin Current. To simulate a Leeuwin Current in a regional coastal model, McCreary et al. (1986) were the first to prescribe an offshore meridional gradient in surface den- sity of approximately $3 \mathrm{~kg} \mathrm{~m}^{-3}$ over a meridional extent of $2000 \mathrm{~km}$. They based this value on observations, and a similar meridional density gradient is found in our eddy-resolving GCM simulations.

Local frontogenesis at gyre scale is stimulated by Ekman transport convergence. That alone would converge the upper layer to the zero wind stress curl line at $35^{\circ} \mathrm{S}$. Negative buoyancy forcing (cooling, evaporation) in the south produces mixed-layer deepening and deceleration of the meridional Ekman velocity. That accelerates the convergence and leads to front formation closer to the Equator than the Ek- 

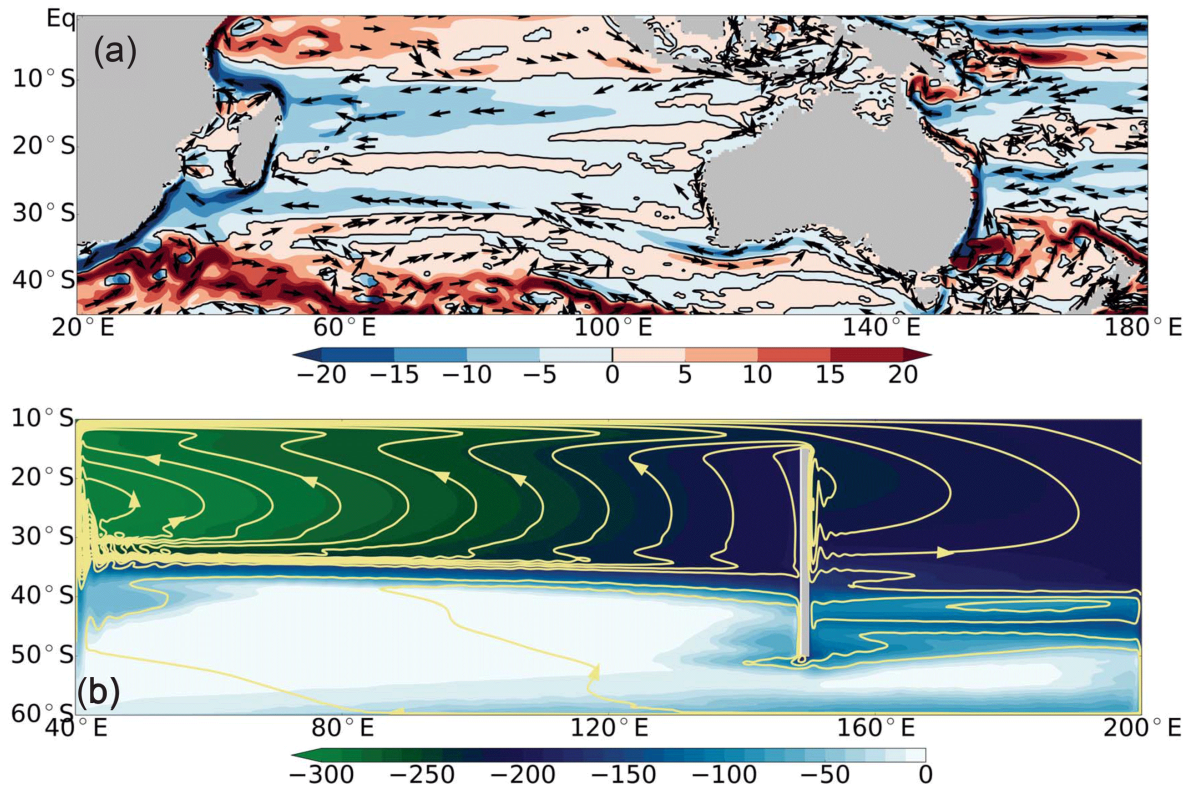

Figure 6. (a) As Fig. 4 with closed Indonesian passages. (b) Stream function (yellow contours, interval $1 \mathrm{~Sv}$ ) of circulation in the upper layer as forced by the configuration shown in Fig. 3 without wind forcing in the eastern basin. Colour shading indicates the depth of the interface relative to the free surface in metres. White areas thus represent areas of (near) outcrop.
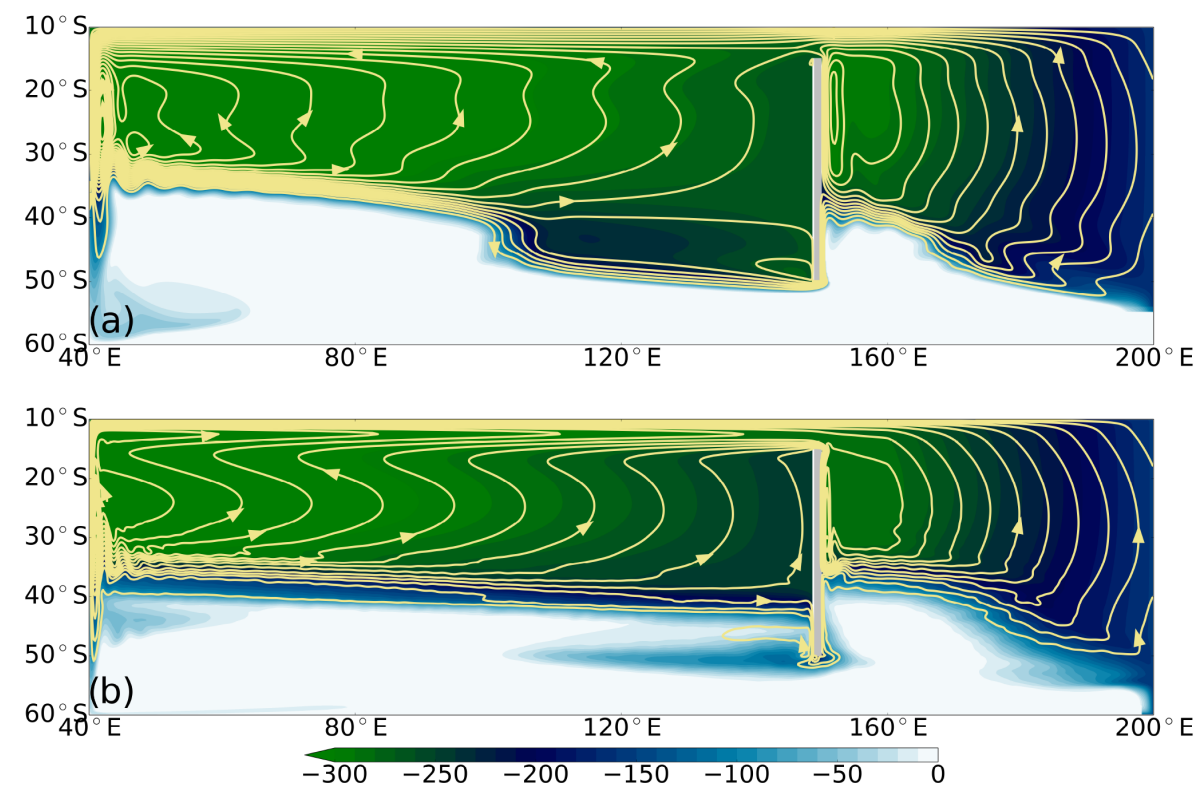

Figure 7. As Fig. 6 including wind forcing in the eastern basin for (a) viscous and (b) inertial circulation.

man convergence line as resolved by the GCM simulations (Fig. 4b).

\section{Sensitivity to Indonesian Throughflow}

Hirst and Godfrey (1993) studied the effect of the ITF by artificially closing the Indonesian passages. This reduced the shallow eastward jet and the transport in the LCS; these results were reproduced with our GCM at coarse resolution (not shown). At eddy-resolving resolution, closure of the Indonesian passages significantly reduces the transport through both the SICC and the LC, as can be seen in Fig. 6a. More importantly, this blocking of the ITF breaks up the connection between the modelled SICC and LC. 
In the conceptual two-layer model, we applied an unconventional method of ITF simulation by wind forcing only over the eastern sector of the Pacific. In that way, inflow from the Pacific can be set to zero without geometrically closing the passages. Closing this passage, as was done in the GCM simulations, essentially changes the topology of the basin. The lack of an ITF gateway induces a southward western boundary current in the eastern basin and could generate leakage south of the island, similar to Tasman leakage, which increases due to blocking of the ITF in the GCM model (Le Bars et al., 2013). The resulting circulation without wind stress over the eastern basin (Fig. 6b) shows a decreased transport along the mid-ocean front. Moreover, the connection between the western and eastern boundary currents is broken.

Without inflow from the eastern basin (ITF), the frontal jet (SICC) merges into the IO gyre. That would be similar to the positioning of the subtropical countercurrents in other basins. Connection with a poleward EBC (the Leeuwin Current) requires circulation around the island. When inflow from the eastern to the western basin is allowed along the north of the island, part of this island circulation is trapped in the upper layer by limited diapycnal transport. It follows the southern boundary of this upper layer, which is the outcrop line.

The evidence collected here supports a view that there is no direct connection of the ITF to the LC. Rather, these currents are connected via the IO western boundary layer (Agulhas) and the SICC. The ITF transport that enters the IO in the north-east and is forced by the wind over the upper layer east of the island has to exit along the southern boundary of this upper layer. The positioning of this boundary is controlled by the wind pattern in combination with the location of the island. That determines the frontal outcrop line and the Leeuwin Current transport jump when the SICC flows into it. The depth-integrated transport agrees with linear theory and follows the western boundary layer all the way to the latitude of zero wind curl in the eastern basin, which is the southern boundary (not shown). To meet these requirements, transport in the lower layer produces a flow against the shallow SICCLC system, which is in agreement with observations where a Leeuwin Undercurrent is found, as well as a westward flow in the sub-thermocline Indian Ocean.

\section{Conclusions}

The GCM experiments reported here show that the basic structure of the flow in the South Indian Ocean is linked to the specific corner-shaped geometry of Australia and Tasmania. Integrating the wind stress curl westward starting at the eastern boundary to determine the Sverdrup transport in the basin, a transport jump results at the south-west corner of Australia. A free zonal boundary layer to the west of the jump matches the unequal Sverdrup regimes (Fig. 4). To the south it is connected with the Agulhas Return Current. The northern edge of the boundary layer is a high shear zone with eastward flow and potential outcropping of the upper layer. This establishes that the SICC and its pathway are largely imposed by the basin geometry combined with the wind pattern.

The wind-driven circulation of the Indonesian Throughflow resides partly in this upper layer, and this fraction is redirected along the front to flow zonally towards the west coast of Australia. Coming in in the north, it merges and retroflects largely with the Agulhas Current and adds to the zonal jet. In the case of outcrop, it is steered to the north of it, across the Indian Ocean, and feeds into the Leeuwin Current. The circulation around Australia, driven by Pacific winds, and the subtropical front in the Indian Ocean can thus account for this anomalously strong poleward eastern boundary current. The experiments with the two-layer conceptual model lend support to this interpretation.

Both models appear to show two qualitatively distinct regimes of flow: a viscous regime, where the zonal flow bends southward towards the south-western point of Australia and no boundary current could be sustained, and an inertial regime, where the front crosses the Indian Ocean zonally and the jet reaches the coast near the latitude where it departs Madagascar and feeds the Leeuwin Current. Although Ekman transport can redirect the Indonesian Throughflow directly into the Leeuwin Current, a process that accounts for the latter's relatively tropical structure, it cannot explain the forcing of the Leeuwin Current. However, more analysis would be required to fully describe the dynamics governing the front position and its coastal trapping.

This system flows around the island circulation of Madagascar and is modified also by buoyancy fluxes at the surface. Local zonal jets may result from Ekman convergence and mixed-layer deepening. However, it is beyond the present study to cover all details of this complex system.

\section{Data availability}

Data from MDT_CNES-CLS13 were produced by CLS Space Oceanography Division and distributed by Aviso, with support from Cnes (http://www.aviso.altimetry.fr/, Aviso, 2016).

Acknowledgements. The authors thank Michael Kliphuis (IMAUUU) for the support with running both models.

Edited by: M. Hecht

\section{References}

Arakawa, A. and Hsu, Y.-J. G.: Energy conserving and potentialenstrophy dissipating schemes for the shallow water equations, Mon. Weather Rev., 118, 1960-1969, 1990. 
Aviso: Aviso Satellite Altimetry Data, available at: http://www. aviso.altimetry.fr/, last access: 1 June 2016.

Benthuysen, J., Furue, R., McCreary, J. P., Bindoff, N. L., and Phillips, H. E.: Dynamics of the Leeuwin Current: Part 2. Impacts of mixing, friction, and advection on a buoyancy-driven eastern boundary current over a shelf, Dynam. Atmos. Oceans, 65, 39-63, doi:10.1016/j.dynatmoce.2013.10.004, 2014.

Cresswell, G. and Golding, T.: Observations of a south-flowing current in the southeastern Indian Ocean, Deep-Sea Res., 27, 449466, doi:10.1016/0198-0149(80)90055-2, 1980.

Csanady, G. T.: The Arrested Topographic Wave, J. Phys. Oceanogr., 8.1, 47-62, doi:10.1175/15200485(1978)008<0047:TATW>2.0.CO;2, 1978.

Csanady, G. T.: "Pycnobathic" Currents over the Upper Continental Slope, J. Phys. Oceanogr., 15, 306-315, doi:10.1175/15200485(1985)015<0306:COTUCS>2.0.CO;2, 1985.

Cushman-Roisin, B.: On the Maintenance of the Subtropical Front and its Associated Countercurrent, J. Phys. Oceanogr., 14, 11791190, 1984.

de Ruijter, W.: Asymptotic Analysis of the Agulhas and Brazil Current Systems, J. Phys. Oceanogr., 12, 361-373, doi:10.1175/1520-0485(1982)012<0361:AAOTAA>2.0.CO;2, 1982.

de Ruijter, W. P. M.: Frontogenesis in an Advective Mixed-Layer Model, J. Phys. Oceanogr., 13, 487-495, 1983.

Dewar, W. K.: Arrested fronts, J. Mar. Res., 49, 21-52, doi:10.1357/002224091784968576, 1991.

Domingues, C. M., Maltrud, M. E., Wijffels, S. E., Church, J. A., and Tomczak, M.: Simulated Lagrangian pathways between the Leeuwin Current System and the upper-ocean circulation of the southeast Indian Ocean, Deep-Sea Res. Pt. II, 54, 797-817, doi:10.1016/j.dsr2.2006.10.003, 2007.

Dukowicz, J. K. and Smith, R. D.: Implicit free-surface method for the Bryan-Cox-Semtner ocean model, J. Geophys. Res., 99, 7991-8014, doi:10.1029/93JC03455, 1994.

Furue, R., McCreary, J. P., Benthuysen, J., Phillips, H. E., and Bindoff, N. L.: Dynamics of the Leeuwin Current: Part 1. Coastal flows in an inviscid, variable-density, layer model, Dynam. Atmos. Oceans, 63, 24-59, doi:10.1016/j.dynatmoce.2013.03.003, 2013.

Gaillard, F. and Charraudeau, R.: New climatology and statistics over the global ocean, MERSEA del, 5, 2008.

Godfrey, J. S. and Golding, T.: The Sverdrup Relation in the Indian Ocean, and the Effect of Pacific-Indian Ocean Throughflow on Indian Ocean Circulation and on the East Australian Current, J. Phys. Oceanogr., 11, 771-779, 1981.

Godfrey, J. S. and Ridgway, K. R.: The Large-Scale Environment of the Poleward-Flowing Leeuwin Current, Western Australia: Longshore Steric Height Gradients, Wind Stresses and Geostrophic Flow, J. Phys. Oceanogr., 15, 481-495, doi:10.1175/1520-0485(1985)015<0481:TLSEOT>2.0.CO;2, 1985.

Hallberg, R.: Time Integration of Diapycnal Diffusion and Richardson Number-Dependent Mixing in Isopycnal Coordinate Ocean Models, Mon. Weather Rev., 128, 1402-1419, doi:10.1175/1520-0493(2000)128<1402:TIODDA>2.0.CO;2, 2000.

Hallberg, R. W.: HIM: The Hallberg Isopycnal Coordinate Primitive Equation Model, NOAA Geophysical Fluid Dynamics Lab- oratory Tech. Report, availablet at: https://www.gfdl.noaa.gov/ cms-filesystem-action/user_files/rwh/him_description.pdf (last access: 27 May 2016), 1997.

Haney, R. L.: Surface Thermal Boundary Condition for Ocean Circulation Models, J. Phys. Oceanogr., 1, 241-248, doi:10.1175/1520-0485(1971)001<0241:STBCFO>2.0.CO;2, 1971.

Hirst, A. C. and Godfrey, J. S.: The Role of Indonesian Throughflow in a Global Ocean GCM, J. Phys. Oceanogr., 23, 1057-1086, doi:10.1175/1520-0485(1994)024<1895:TRTASC>2.0.CO;2, 1993.

Hurrell, J. W., Hack, J. J., Shea, D., Caron, J. M., and Rosinski, J.: A new sea surface temperature and sea ice boundary dataset for the community atmosphere model, J. Climate, 21, 5145-5153, doi:10.1175/2008JCLI2292.1, 2008.

Jia, F., Wu, L., and Qiu, B.: Seasonal Modulation of Eddy Kinetic Energy and Its Formation Mechanism in the Southeast Indian Ocean, J. Phys. Oceanogr., 41, 657-665, doi:10.1175/2010JPO4436.1, 2011.

Kobashi, F. and Kubokawa, A.: Review on North Pacific Subtropical Countercurrents and Subtropical Fronts: Role of mode waters in ocean circulation and climate, J. Oceanogr., 68, 21-43, doi:10.1007/s10872-011-0083-7, 2012.

Large, W. G. and Yeager, S. G.: Diurnal to decadal global forcing for ocean and sea-ice models: The data sets and flux climatologies, NCAR Tech. Note, TN-460+ST, 105 pp., doi:10.5065/D6KK98Q6, 2004.

Le Bars, D., Dijkstra, H. A., and De Ruijter, W. P. M.: Impact of the Indonesian Throughflow on Agulhas leakage, Ocean Sci., 9, 773-785, doi:10.5194/os-9-773-2013, 2013.

Maltrud, M., Bryan, F., and Peacock, S.: Boundary impulse response functions in a century-long eddying global ocean simulation, Environ. Fluid Mech., 10, 275-295, doi:10.1007/s10652009-9154-3, 2010.

McCreary, J. P., Shetye, S. R., and Kundu, P. K.: Thermohaline forcing of eastern boundary currents: With application to the circulation off the west coast of Australia, J. Mar. Res., 44, 71-92, doi:10.1357/002224086788460184, 1986.

McCreary, J. P., Miyama, T., Furue, R., Jensen, T., Kang, H. W., Bang, B., and Qu, T.: Interactions between the Indonesian Throughflow and circulations in the Indian and Pacific Oceans, Prog. Oceanogr., 75, 70-114, doi:10.1016/j.pocean.2007.05.004, 2007.

Menezes, V. V., Phillips, H. E., Schiller, A., Domingues, C. M., and Bindoff, N. L.: Salinity dominance on the Indian Ocean Eastern Gyral current, Geophys. Res. Lett., 40, 5716-5721, doi:10.1002/2013GL057887, 2013.

Merle, J., Rotschi, H., and Voituriez, B.: Zonal Circulation in the Tropical Western South Pacific at 170E, B. Jpn. Soc. Sci. Fish., 91-98, 1969.

Morrow, R. and Birol, F.: Variability in the southeast Indian Ocean from altimetry: forcing mechanisms for the Leeuwin Current, J. Geophys. Res.-Oceans, 103, 18529-18544, doi:10.1029/98JC00783, 1998.

Nauw, J. J., van Aken, H. M., Webb, A., Lutjeharms, J. R. E., and de Ruijter, W. P. M.: Observations of the southern East Madagascar Current and undercurrent and countercurrent system, J. Geophys. Res.-Oceans, 113, 1-15, doi:10.1029/2007JC004639, 2008. 
Palastanga, V., van Leeuwen, P. J., Schouten, M. W., and de Ruijter, W. P. M.: Flow structure and variability in the subtropical Indian Ocean: Instability of the South Indian Ocean countercurrent, J. Geophys. Res.-Oceans, 112, 1-11, doi:10.1029/2005JC003395, 2007.

Pedlosky, J., Pratt, L. J., Spall, M. A., and Helfrich, K. R.: Circulation around islands and ridges, J. Mar. Res., 55, 1199-1251, 1997.

Reid, J. L. and Mantyla, A. W.: On the Mid-Depth Circulation of the North Pacific Ocean, J. Phys. Oceanogr., 8, 946-951, doi:10.1175/1520-0485(1978)008<0946:OTMDCO>2.0.CO;2, 1978.

Ridgway, K. R. and Dunn, J. R.: Observational evidence for a Southern Hemisphere oceanic supergyre, Geophys. Res. Lett., 34, 1-5, doi:10.1029/2007GL030392, 2007.

Schouten, M. W., de Ruijter, W. P. M., and Ridderinkhof, H.: A seasonal intrusion of subtropical water in the Mozambique Channel, Geophys. Res. Lett., 32, 1-4, doi:10.1029/2005GL023131, 2005.

Smith, R. L., Huyer, A., Godfrey, J. S., and Church, J. A.: The Leeuwin Current off Western Australia, 1986-1987, J. Phys. Oceanogr., 21, 323-345, doi:10.1175/15200485(1991)021<0323:TLCOWA>2.0.CO;2, 1991.

Song, Q., Gordon, A. L., and Visbeck, M.: Spreading of the Indonesian Throughflow in the Indian Ocean*, J. Phys. Oceanogr., 34, 772-792, doi:10.1175/15200485(2004)034<0772:SOTITI>2.0.CO;2, 2004.

Speich, S., Blanke, B., and Cai, W.: Atlantic meridional overturning circulation and the Southern Hemisphere supergyre, Geophys. Res. Lett., 34, 1-5, doi:10.1029/2007GL031583, 2007.

Takeuchi, K.: Numerical Study of the Subtropical Front and the Subtropical Countercurrent*, Journal of the Oceanographical Society of Japan, 40, 371-381, 1984.

Tsuchiya, M.: Evidence of a double-cell subtropical gyre in the South Atlantic Ocean, J. Mar. Res., 43, 57-65, doi:10.1357/002224085788437271, 1985.
Uda, M. and Hasunuma, K.: The Eastward Subtropical Countercurrent in the Western North Pacific Ocean, J. Oceanogr. Soc. Japan, 25, 201-210, 1969.

Valsala, V. K. and Ikeda, M.: Pathways and effects of the Indonesian Throughflow water in the Indian Ocean using particle trajectory and tracers in an OGCM, J. Climate, 20, 2994-3017, doi:10.1175/JCLI4167.1, 2007.

van Sebille, E., Sprintall, J., Schwarzkopf, F. U., Gupta, A. S., Santoso, A., England, M. H., Biastoch, A., and Böning, C. W. Pacific-to-Indian Ocean connectivity: Tasman leakage, Indonesian Throughflow, and the role of ENSO, J. Geophys. ResOceans, 1365-1382, doi:10.1002/2013JC009525, 2014.

Waite, A., Thompson, P., Pesant, S., Feng, M., Beckley, L., Domingues, C., Gaughan, D., Hanson, C., Holl, C., Koslow, T., et al.: The Leeuwin Current and its eddies: An introductory overview, Deep-Sea Res. Pt. II, 54, 789-796, 2007.

Weaver, A. J. and Middleton, J. H.: On the Dynamics of the Leeuwin Current, J. Phys. Oceanogr., 19, 626-648, doi:10.1175/1520-0485(1989)019<0626:OTDOTL>2.0.CO;2, 1989.

Weller, E., Holliday, D., Feng, M., Beckley, L., and Thompson, P.: A continental shelf scale examination of the Leeuwin Current off Western Australia during the austral autumn-winter, Cont. Shelf Res., 31, 1858-1868, doi:10.1016/j.csr.2011.08.008, 2011.

Woo, M. and Pattiaratchi, C.: Hydrography and water masses off the western Australian coast, Deep-Sea Res., 55, 1090-1104, doi:10.1016/j.dsr.2008.05.005, 2008.

Woo, M., Pattiaratchi, C., and Schroeder, W.: Dynamics of the Ningaloo Current off Point Cloates, Western Australia, Mar. Freshwater Res., 57, 291-301, doi:10.1071/MF05106, 2006. 